\title{
SHEAR STRENGTHENING OF R. C. T- BEAMS BY MEANS OF CFRP SHEETS
}

\section{Omar Ahmed Farghal}

Associate Professor, Civil Engineering Department, Assiut University, Assiut, P.O.Box71516, Egypt, E-mail: omar_farghal222@yahoo.com

(Received April 14, 2012 Accepted May 19, 2012)

This research aimed to experimentally investigate the contribution of bonded web carbon fiber reinforced polymer (CFRP) sheets to the shear strength of reinforced concrete (RC) T-beams. Two strengthening techniques using CFRP strips were applied along the shear-span zone: the first one is vertical $U$-jacket and the later is vertical strips bonded to the beam sides only. Fibers of both $U$ jacket and side sheets were vertically oriented $\left(\theta \square=90^{\circ}\right)$. Test results showed that the strengthening technique with U-jacket CFRP sheets improved the shear strength particularly. Three mechanisms of failure were recognized for the tested beams depending upon the end condition of the bonded CFRP sheet. Although the failure mode for the different beams was a brittle one, the strengthened beams provided with U-jacket CFRP sheets showed more or less a ductile behavior at a higher loading level up to a load level just before failure. As a consequence, these beams approved an acceptable enhancement in the structural ductility. Moreover, the obtained results concerning the strains induced in the CFRP sheets are used to study the applicability of the mathematical model suggested by the ACI code [1, 2].

Keywords: Carbon Fiber Reinforced polymer (CFRP); delamination; strengthening; anchorage.

\section{INTRODUCTION}

The technique of externally bonding carbon fiber reinforced polymer (CFRP) is applied more and more, and becomes an attractive solution for strengthening /retrofitting the reinforced concrete (RC) structures. This due to the good properties and characteristics of carbon fiber reinforced polymer (CFRP) sheets such as: noncorrosiveness; easy to be bent and wrapped; lightweight; higher strength in comparison to the traditional reinforcement (steel plates). Moreover, the simplicity of application in a wide variety without any special precautions and conditions, which are considered so necessary to apply the conventional strengthening technique, e.g. steel plate technique. Also, under certain environmental condition, steel plating has been demonstrated to be vulnerable to corrosion especially at steel plate-epoxy interface, as well as the limited available length of steel plates may cause some problems in typical situations [3]. Hence, externally bonded CFRP sheets technique has been the adequate substitute for that of steel plates and it can solve problems and difficulties, which obstruct the application of steel plate technique in some situations. 
In multistory building, generally, the beams used in the lower floors resist high shear forces during earthquakes. This results in close spacing of internal stirrups that may violate spacing requirements given in codes for proper placing of concrete. By using FRP reinforcement, especially CFRP sheets, bonded to the web of RC, the designers can increase the spacing of internal stirrups, and both the shear capacity and the cracking behavior can be improved. This technique can be used in repair and retrofit of existing beams, as well as in designing new RC beams. Several studies [415] have been conducted to study experimentally and analytically the behavior of RC beams having a rectangular cross-section and strengthened in shear with FRP reinforcements, and few is known about those dealing with the behavior of strengthened beams having T-cross-section, e.g. $[16,17]$. Moreover, the different studies derived different expression to predict the effective strain induced in the bonded web sheets; the contribution of the bonded web reinforcement to the shear strength depends mainly on such effective strain.

In this paper, tests on six RC beams with T- cross-section and strengthened in shear with externally bonded CFRP sheets were conducted to study the contribution of the bonded sheets to the shear strength of RC T-beams. Also, the influence of the examined strengthening technique on both the ductility and failure mode was defined. Moreover, the induced strain values in the CFRP sheets were utilized to study the applicability of the mathematical model suggested by the ACI code $[1,2]$ to predict the effective strains induced in the CFRP sheets.

\section{EXPERIMENTAL STUDIES}

\section{Layout of Experiments and Materials}

The behavior of RC T-beams deficient in shear strength and strengthened with externally bonded web CFRP sheets was investigated by conducting two-point loading bending test on six beams over a simple span of $2000 \mathrm{~mm}$, in which the effective depth $(d)$ is $280-\mathrm{mm}$ and shear-span to depth ratio $(a / d)$ equals 2.5 . All the tested models (CS.O, CS.1, CS.2, DS.O, DS.1 and DS.2) have an identical T-cross-section: flange width and thickness are 450 and $70-\mathrm{mm}$, respectively, web width is $150-\mathrm{mm}$, and total section height is $320-\mathrm{mm}$. Main reinforcement of all tested beams were $4 \Phi \square 18$ $\mathrm{mm}$ (Steel 360/520) in the tension side; in addition, four rebars of 8-mm-diameter (Steel 240/350)are used as compression reinforcement. Young's modulus of the tension and compression rebars is $215 \mathrm{GPa}$ and $208 \mathrm{GPa}$, respectively. No internal stirrups was provided along the shear-span of the samples CS.O, CS.1 and CS.2; on the other hand, internal stirrups of 6-mm-diameter and 140-mm spacing (Steel 240/350 and Young's modulus $\approx 205 \mathrm{GPa}$ ) were provided along the shear-span in case of DS.O, DS. 1 and DS.2, see Figs. 1 and 2 as well as Table 1.

CS.O and DS.O were tested in their original condition to serve as control samples (without strengthening). These beams were designed to fail mainly due to shear. Beams CS.1 and DS.1 were strengthened with twelve CFRP strips of 100-mm width and 200$\mathrm{mm}$ spacing (six strips per shear-span). These strips of CFRP sheets were bonded to the two sides of the beam. However, Beams CS.2 and DS.2 were strengthened with the same effective cross-sectional area of fiber sheets of $78 \mathrm{~mm}^{2}$ per shear-span (three Ujacket strips each of $100 \mathrm{~mm}$ in width). Both the U-jacket and strips were with the 
fibers oriented vertically $\left(\theta=90^{\circ}\right)$ and distributed uniformly along the shear-span of the beam, Figs. 3 and 4.

The tested beams were cast using a concrete mix achieving mean splitting strength and Young's modulus of 2.85 and $23000 \mathrm{~N} / \mathrm{mm}^{2}$, respectively. The mean compressive strength for the standard cylinder $\left(f_{c}\right)$ and cube $\left(f_{c}\right)$ after 28 days for the tested beams were listed in Table 1.

Table 1: Data of tested beams

\begin{tabular}{|c|c|c|c|c|c|}
\hline \multirow{2}{*}{$\begin{array}{l}\text { Beam } \\
\text { No. }\end{array}$} & \multicolumn{4}{|c|}{ Beam Data } & \multirow{2}{*}{$\begin{array}{c}\text { Shear Strengthening } \\
\text { per Shear Span }\end{array}$} \\
\hline & $\begin{array}{c}f_{c} \\
\left(\mathbf{N} / \mathbf{m m}^{2}\right)\end{array}$ & $\begin{array}{c}f_{c}^{\prime} \\
\left(\mathbf{N} / \mathbf{m m}^{2}\right)\end{array}$ & $A_{s}$ & $\begin{array}{l}\text { Internal } \\
\text { Stirrups }\end{array}$ & \\
\hline CS.O & 31.0 & 26.7 & \multirow{3}{*}{$4 \Phi 18 \mathrm{~mm}$} & \multirow{3}{*}{$\begin{array}{l}\text { No stirrups } \\
\text { along shear- } \\
\text { span }\end{array}$} & Control Beam 1 \\
\hline CS.1 & 30.5 & 26.2 & & & $\begin{array}{c}6 \text { strips, each of } 100 \mathrm{~mm} \\
\text { width, see Fig.3 }\end{array}$ \\
\hline CS.2 & 30.5 & 26.2 & & & $\begin{array}{l}3 \text { U-jacket strips, each of } \\
100 \mathrm{~mm} \text { width, see Fig. }\end{array}$ \\
\hline DS.O & 31.0 & 26.7 & \multirow{3}{*}{$4 \Phi 18 \mathrm{~mm}$} & \multirow{3}{*}{$\begin{array}{c}\text { Stirrups } \\
\phi 6-\mathrm{mm} \\
\text { of } 140-\mathrm{mm} \\
\text { spacing }\end{array}$} & Control Beam 2 \\
\hline$D S .1$ & 31.5 & 27.1 & & & $\begin{array}{c}6 \text { strips, each of } 100 \mathrm{~mm} \\
\text { width, see Fig. } 3\end{array}$ \\
\hline$D S .2$ & 31.5 & 27.1 & & & $\begin{array}{l}3 \text { U-jacket strips, each of } \\
100 \mathrm{~mm} \text { width, see Fig. }\end{array}$ \\
\hline
\end{tabular}

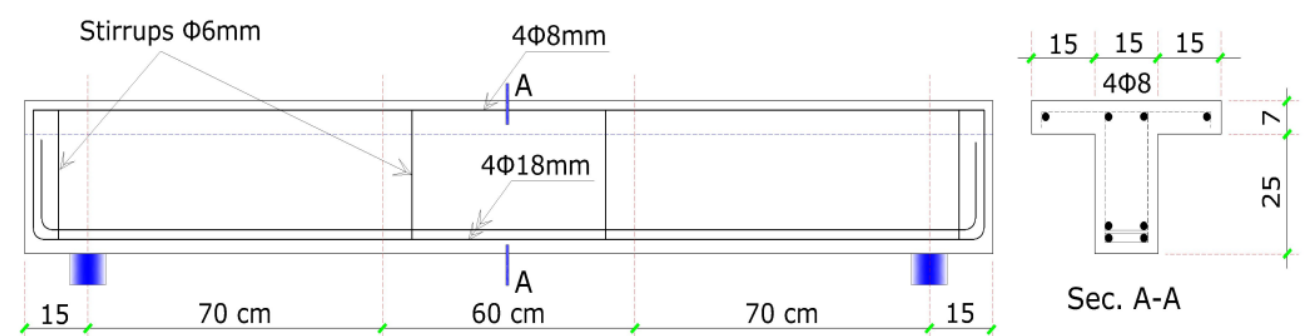

Fig. 1: Details of internal reinforcement for tested beams: CS.0, CS.1 \& CS.2.

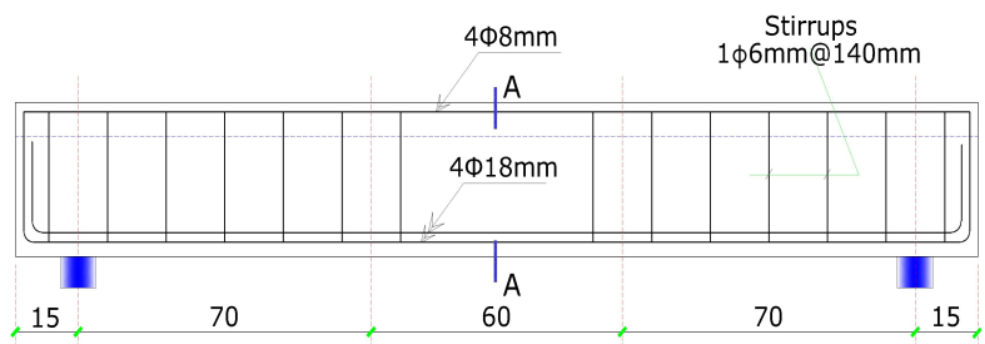

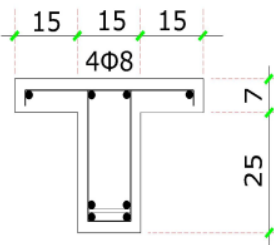

Sec. A-A

Fig. 2: Details of internal reinforcement for tested beams: DS.0, DS.1 \& DS.2 


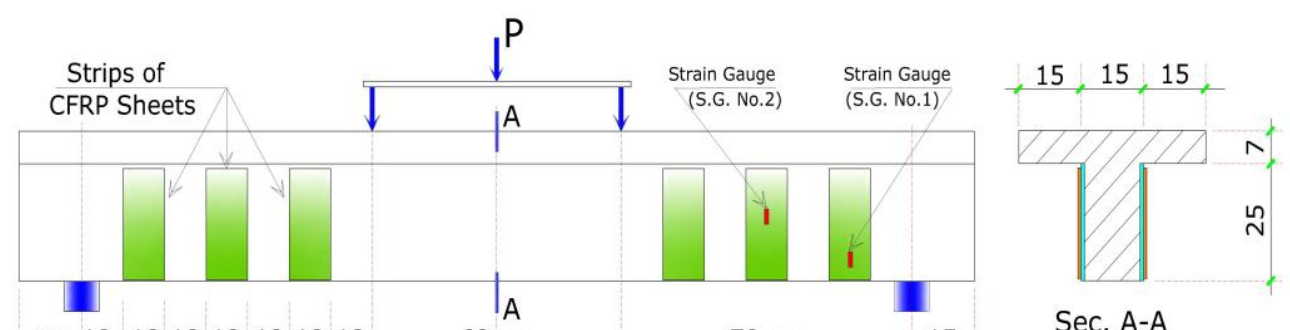

$1510,10,10,10,10,10,10, \quad 60 \mathrm{~cm}, \quad 70 \mathrm{~cm}, \quad 15, \quad$ Sec. A-A

Fig. 3: Details and arrangements of bonded CFRP sheets for tested beam CS.1 \& DS.1

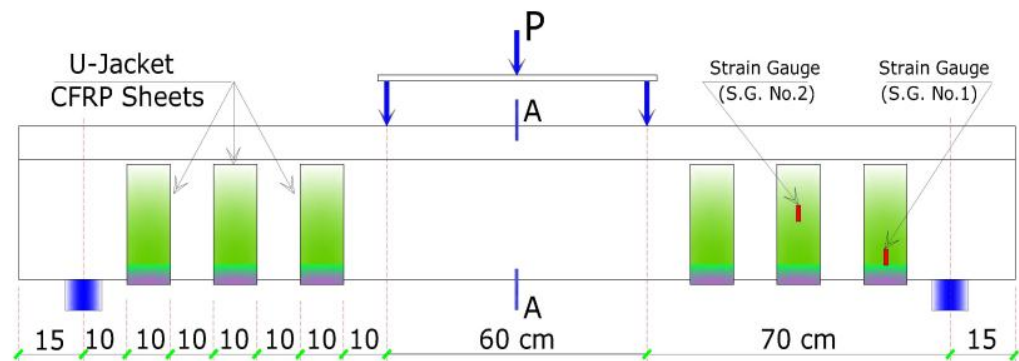

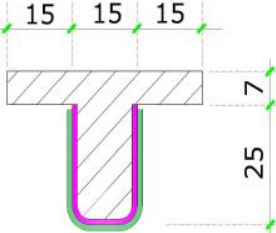

Sec. A-A

Fig. 4: Details and arrangements of bonded CFRP sheets for tested beam CS.2 \& DS.2

The external reinforcement was a CFRP sheet [18]. Such CFRP sheet is available in rolled sheet of $0.13-\mathrm{mm}$ effective thickness, 300-mm width and 50-m length. The effective thickness gives the section of the fibres in each single ply. The rupture strength, ultimate (= failure) strain and Young's modulus of such CFRP sheet are 3500 $\mathrm{N} / \mathrm{mm}^{2}, 15.2 \mathrm{~mm} / \mathrm{m}(=15.2 \%$ o $)$ and $230000 \mathrm{~N} / \mathrm{mm}^{2}$, respectively.

An epoxy mortar layer of about 2-mm thickness was applied to all the strengthened beams as a substratum to the CFRP sheets [18]. This epoxy mortar is completely cured within a period of 24 hours after application. The compressive, bending and tensile strengths of this mortar are 80,20 and $6.5 \mathrm{~N} / \mathrm{mm}^{2}$ respectively.

The beams were prepared for bonding after a period of three weeks from casting. The surfaces to be strengthened were roughened using a grinding technique. Moreover, in case of strengthened beams provided with U-jacket sheets, the corners where the Ujacket sheets were applied had been rounded in a curved shape of about 50-mmdiameter. Before the application of epoxy mortar layer, the roughened surfaces were cleaned by brushing and compressed air to remove any attached fine materials.

\section{EXPERIMENTAL RESULTS AND DISCUSSIONS}

Table 2 includes a summary of the observed behavior for the tested models at cracking and maximum conditions. For instance, load at which the flexural crack initiated $\left(P_{c r, f l e x}\right)$, load corresponding to the commencement of a significant inclined crack $\left(P_{c r, s h}\right)$, and the increase in the service load $\left(R_{s e r}\right)$ over the counterpart in the control beams are listed in Table 2 . The service load $P_{s e r}\left(=P_{c r, s h}\right)$ is expressed by the 
load at which the significant inclined crack initiated. Moreover, Table 2 contains other results concerning the ultimate condition such as: maximum load $\left(P_{\max }\right)$; increase in the maximum load over that of the control beam $\left(R_{\max }\right)$; ductility index based on the service load $\left(\mu_{D}\right)$; mid-span strain in the bottom fiber (at tension reinforcement's level) corresponding to the maximum load $\left(\varepsilon_{s, \text { max }}\right)$; maximum strain induced in the bonded CFRP strips corresponding to the maximum load $\left(\varepsilon_{f, \max }\right)$; mean strain in the bonded CFRP strips corresponding to the maximum load $\left(\varepsilon_{f, \text { mean }}\right)$; and failure mode.

Table 2: Cracking and maximum load conditions of the tested beams

\begin{tabular}{|c|c|c|c|c|c|c|c|c|c|c|}
\hline \multirow{2}{*}{$\begin{array}{c}\text { Beam } \\
\text { No. }\end{array}$} & \multicolumn{3}{|c|}{$\begin{array}{l}\text { Cracking Load } \\
\text { Condition }\end{array}$} & \multicolumn{5}{|c|}{$\begin{array}{c}\text { Maximum Load } \\
\text { Condition }\end{array}$} & \multirow{2}{*}{$\begin{array}{c}\text { Ductility } \\
\mu_{D} \\
\left(\Delta_{1} / \Delta_{2}\right)\end{array}$} & \multirow{2}{*}{$\begin{array}{c}\text { Failure } \\
\text { Mode }\end{array}$} \\
\hline & $\begin{array}{c}P_{c r, f l e x} \\
(\mathbf{k N})\end{array}$ & $\begin{array}{c}P_{c r, s h} \\
=P_{s e r} \\
(\mathbf{k N})\end{array}$ & $\begin{array}{l}R_{\text {ser }} \\
(\%)\end{array}$ & $\begin{array}{l}P_{\max } \\
(\mathbf{k N})\end{array}$ & $\begin{array}{l}\boldsymbol{R}_{\max } \\
(\%)\end{array}$ & $\begin{array}{l}\varepsilon_{\text {s.max }} \\
(\%)\end{array}$ & $\begin{array}{l}\varepsilon_{f \cdot \max } \\
(\%)\end{array}$ & $\begin{array}{l}\varepsilon_{f, m e a n} \\
(\%)\end{array}$ & & \\
\hline CS.0 & 80 & 90 & --- & 160 & --- & 2.27 & --- & --- & 2.16 & Mech.1 \\
\hline CS. 1 & 90 & 100 & 11.1 & 190 & 18.8 & 2.81 & 2.81 & 2.65 & 2.45 & Mech.2 \\
\hline CS. 2 & 90 & 110 & 22.2 & 201 & 25.6 & 3.31 & 4.85 & 4.21 & 2.86 & Mech.3 \\
\hline DS.0 & 80 & 110 & --- & 215 & --- & 3.01 & --- & --- & 2.94 & Mech.1 \\
\hline DS. 1 & 80 & 120 & 9.1 & 254 & 18.1 & 3.58 & 2.34 & 2.27 & 3.58 & Mech. 2 \\
\hline DS. 2 & 90 & 130 & 18.2 & 278 & 29.3 & 3.95 & 6.60 & 4.15 & 4.06 & Mech.3 \\
\hline
\end{tabular}

Note: $\Delta_{1} \& \Delta_{2}=$ deflections corresponding to peak and service loads respectively, Mech.1, Mech.1, and Mech.1 = the first, second, and third failure Mechanism respectively, see the following section.

\section{Failure Behavior and Strength}

For each group of the tested beams, both the control and strengthened beams showed, at first, a linear elastic behavior. Afterward, commencement of cracks was only within the shear-span (shear crack) of the control beam CS.0; however in case of the other tested beams (DS.0, CS.1, CS.2, DS.1, and DS.2) the first crack initiated as a flexural one within the central region of the constant moment. Thereafter, a non-linear stage was recorded with the development of numerous flexural cracks along the middle region of a constant moment. Also, as the applied load increased, a number of flexural shear and shear cracks was developed along the shear spans of the examined models. As a matter of fact, at the same loading levels, the number of shear cracks was fewer in case of the strengthened beams in comparison to the corresponding control one, see Figs. 5 and 6.

Three failure mechanisms were recognized for the tested beams. The first one was the traditional brittle shear failure in case of the control samples (CS.O \& DS.O). The second mechanism was noticed in the samples CS.1\& DS.1 where shear failure was accompanied with a partial cover delamination of the outer and middle CFRP sheets. The third mechanism was a shear one accompanied with cut off the outer CFRP sheet 
as well as crushing of concrete in the shear crack path's region. Such a failure mechanism was observed in U-jacketed beams (CS.2 \& DS.2), see Figs. 5 and 6.

All the strengthened beams CS.1, CS.2, DS.1 and DS.2 exhibited the first flexural crack approximately at the same load level and shared the same flexural stiffness as their corresponding control beams CS.O \& DS.O. Results showed that the behavior of the strengthened beams were quite comparable to that of the corresponding control beam up to a load level approximately corresponding to the shear cracking load level, see Figs. 7 and 8 . In other words, the flexural stiffness was not influenced significantly by the applied strengthening technique, particularly at lower loading levels. This could be attributed to the fact that the applied strengthening system, either U-jackets sheets or that bonded to the sides only, was not only have a small flexural stiffness but was applied not continuously along the beam length as well. As a result, the flexural stiffness in terms of the mid-span deflection was not affected reasonably. But, at higher loading levels, since the applied strengthening technique decreased the number of cracks and constrained their propagations, the strengthened beams showed a slight enhancement in the flexural stiffness, particularly in case of beams provided with Ujackets CFRP sheets, see Figs. 7 and 8.

It is interesting to mention that the strengthened beams with $\mathrm{U}$-jacket showed a slight ductile behavior before failure. As a consequence, the strain induced in tension bars was approaching considerably to the yielding value, especially in case of beams provided with internal stirrups (DS.2), see Fig. 8 .
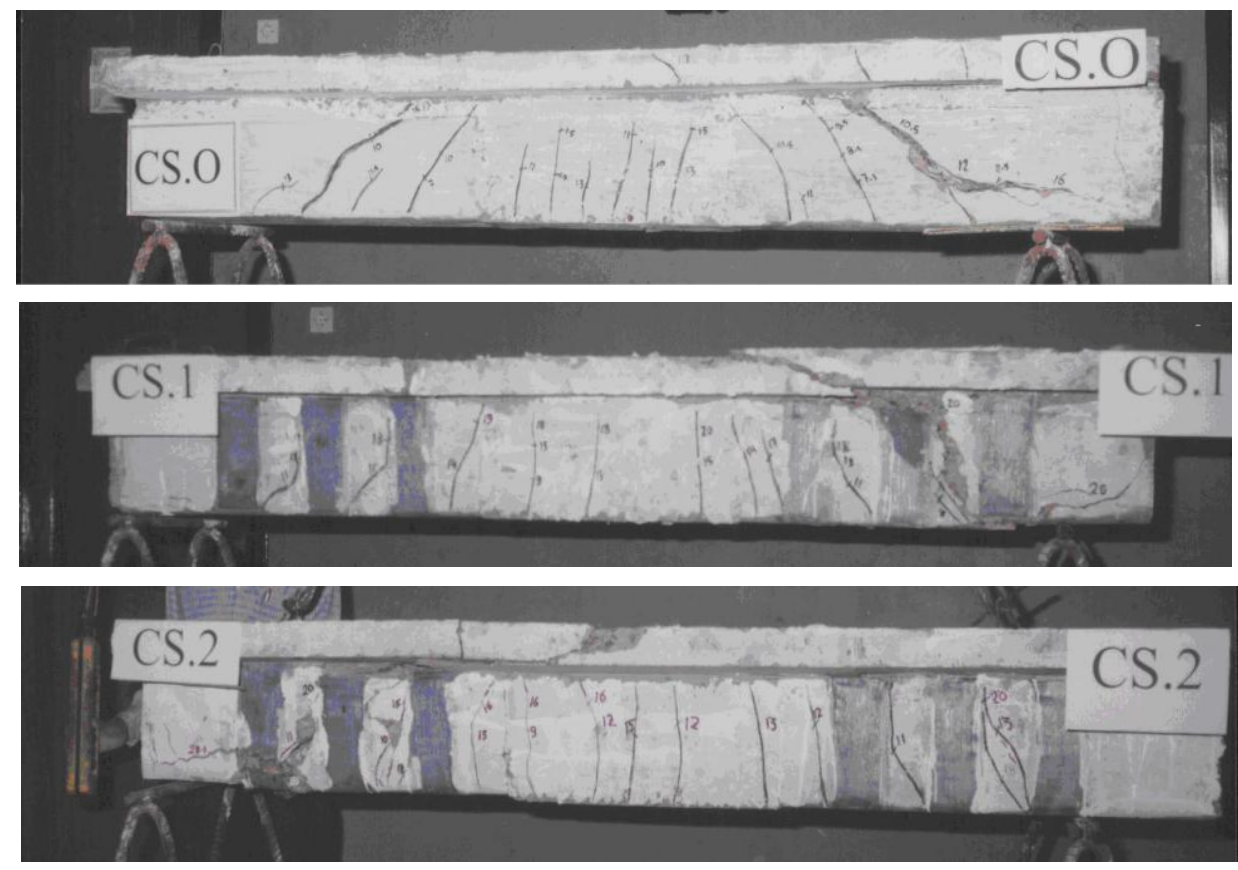

Fig. 5: Cracks pattern of beams CS.0, CS.1 \& CS.2. 

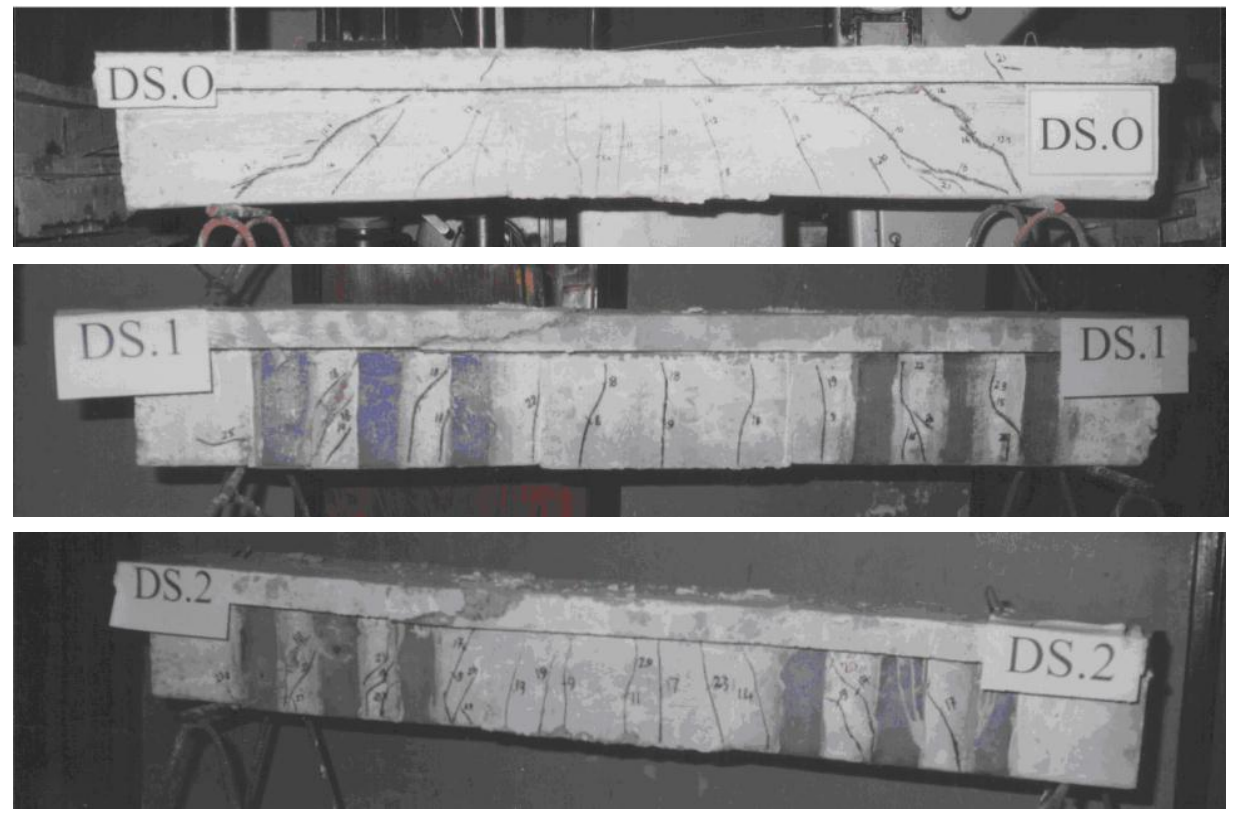

Fig. 6: Cracks pattern of beams DS.0, DS.1 \& DS.2.

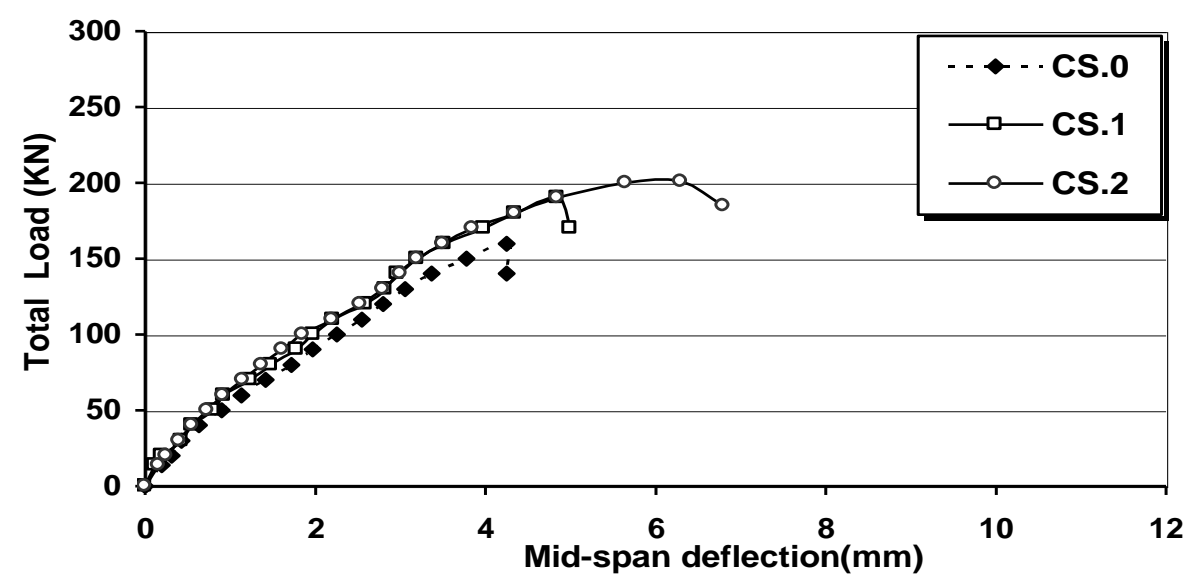

Fig. 7: Load mid-span deflection for beams: CS.0, CS.1 \& CS.2.

With respect to service load condition, the strengthened beams showed an improvement in the service load $P_{\text {ser }}$ values. For instance, the service loads of the beams CS.1, CS.2, DS.1 and DS.2 are higher than that of the corresponding control samples by $11.1,22.2,9.1$ and $18.2 \%$, respectively, see Table 2 . On the other hand, when considering the maximum load condition, the strengthened beams achieved maximum load $\left(P_{\max }\right)$ higher than the corresponding control one by $18.8,25.6,18.1$ and $29.3 \%$ in case of beams CS.1, CS.2, DS. 1 and DS.2 respectively, see Table 2 and Fig. 9. 


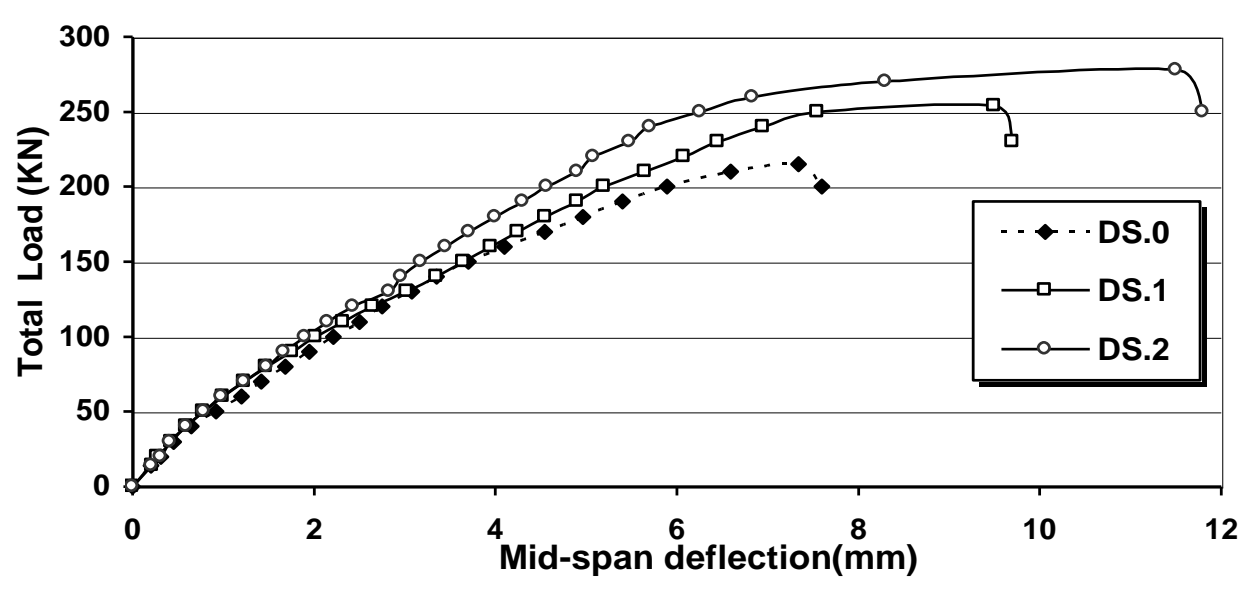

Fig. 8: Load mid-span deflection for beams: DS.0, DS.1 \& DS.2

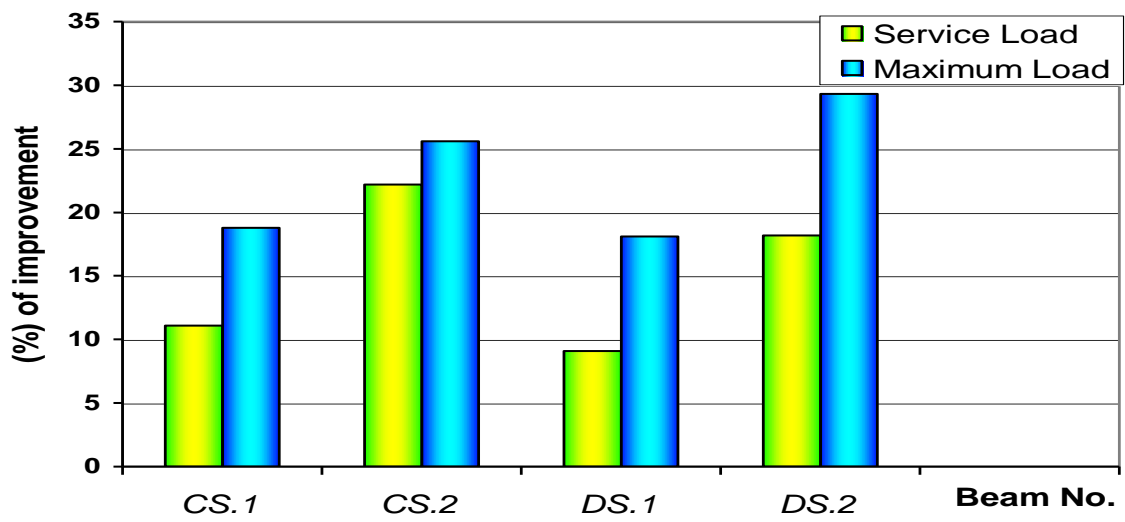

Fig. 9: Increase in both service and maximum loads for strengthened beams.

\section{Strains in CFRP Sheets and Strengthening Efficiency}

By means of strain gauges fixed on CFRP sheets at the positions of the shear crack occurred in case of the corresponding control one, the values of the strains induced in the CFRP sheets, either U-jacket sheets or that bonded to the sides only, were measured for the different CFRP strips (strain gauge No.1 (SG.1) for the outer strips, strain gauge No.2 (SG.2) for the neighbored strips), see Figs. 3 and 4. The results of these measurements are shown in Figs. 10 and 11. These figures clearly illustrate the variation of the strain induced in CFRP strips from zero loading up to failure. It is clear that SG.1 recorded the highest strain values, because the main shear crack initiated and propagated close to the location of the gauge; on the other side, lower values were recorded in SG.2, particularly for beams provided with U-jacket sheets "CS.2 \& DS.2". It is worthwhile to notice that the CS.2 \& DS.2 showed higher CFRP strains in comparison to that provided with CFRP sheets bonded to the sides of the samples CS.1 $\& D S .1$. The outer strips in case of beams provided with $\mathrm{U}$-jacket sheets showed a 
maximum efficiency where a cut-off in CFRP sheets occurred just before failure; however, for CS.1 \& DS.1, a local cover delamination was occurred in the outer strips. This result could be attributed to the anchorage length of the bonded strips, where Ujacket provided a reasonable anchorage length for the bonded strips in comparison with the strips bonded to the beam sides only. It is worth mentioning that, for the models CS. $2 \&$ DS.2, the records of SG.1 did not measure the maximum strain values induced in the CFRP sheets because the location of such strain gauges was a way from the main shear crack's path where a cut-off in CFRP sheet occurred.

From Table 2, it is clear that the strengthened beams provided with internal stirrups showed an increase in the maximum load higher than that provided with no internal stirrups. For instance, the maximum load of the strengthened beams CS. $1 \&$ CS.2, with no internal stirrups, was higher than that of the reference beam by 30 and $41 \mathrm{kN}$, respectively. However, 39 and $63 \mathrm{kN}$ were the difference in maximum load between the strengthened beams and provided with internal stirrups and the corresponding control beam, respectively. From the author's point of view, this effect is related to the existing internal stirrups which insure a good performance and contribution for the applied strengthening technique through controlling both the shear crack width and the loss of the aggregate interlock.

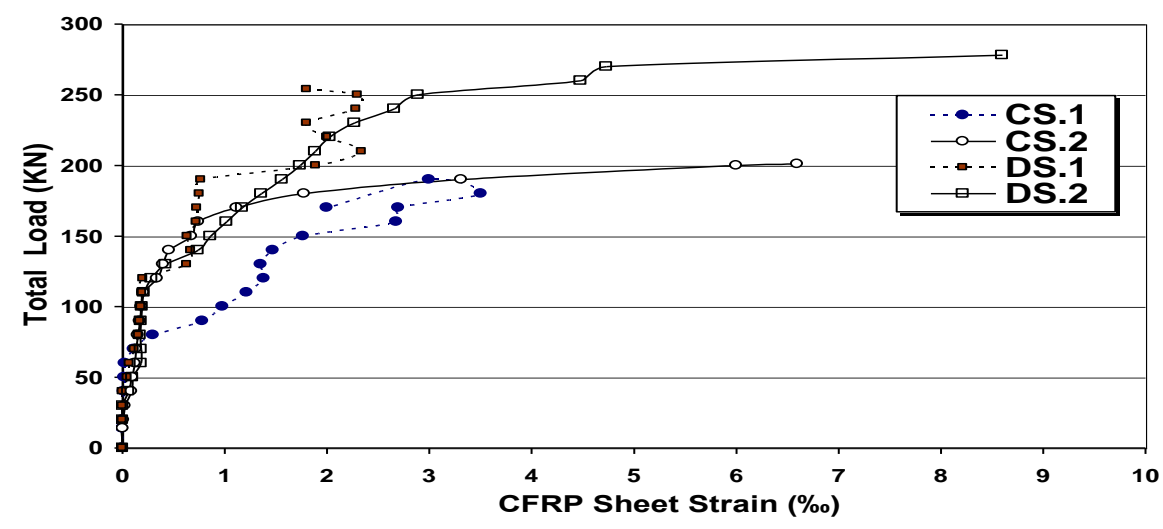

Fig.10: Load versus strain induced in the outer CFRP strips (SG. No.1)

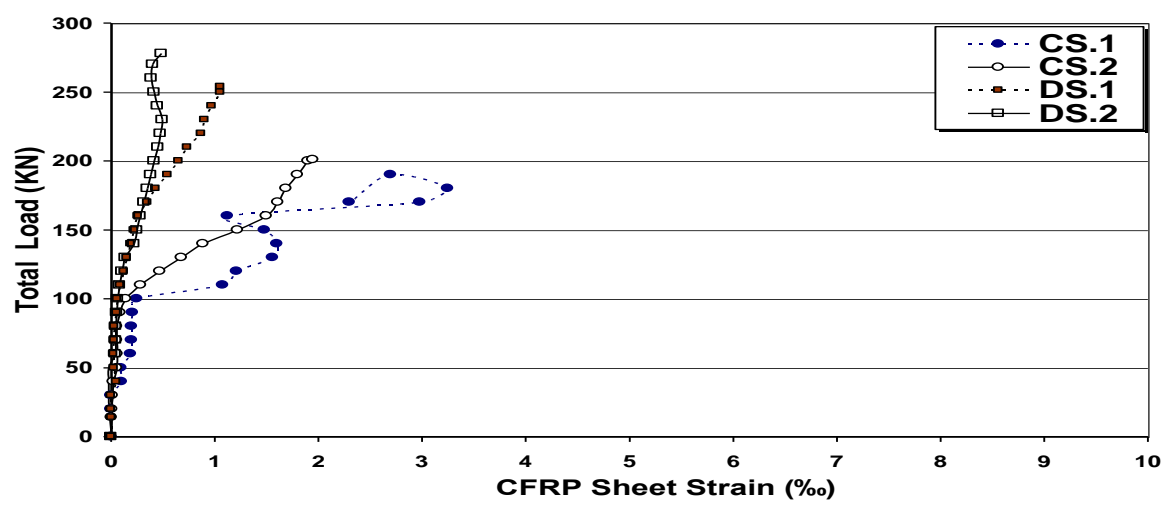

Fig. 11: Load versus strain induced in the middle CFRP strips (SG. No.2) 
The real contribution of the bonded CFRP strips to the total load $P_{f,}\left(=2 V_{f}\right)$ may be calculated according to Eq. (1), by considering that the effective CFRP strains $\varepsilon_{f, e f f}$ equals the measured mean CFRP strain $\varepsilon_{f \text {,mean }}$ recorded in Table 2 , where $\varepsilon_{f \text {,mean }}$ is the mean CFRP strain for all strips located along the main shear crack at failure. The mean strain of the bonded CFRP strips can be estimated from the measured CFRP strains by taking into account the mean value of the maximum recorded strain of the CFRP strips located in the path of the main shear crack "the outer two CFRP sheet strips". It is interesting to mention here that, due to the fact that the anchorage length of CFRP strips bonded to the sides only (CS.1 \& DS.1) was not enough, the maximum strains of the CFRP sheets did not reach its maximum value "15.2 $\mathrm{mm} / \mathrm{m}(=15.2 \%) "$ and thus the contribution of the externally bonded CFRP sheets did not fulfill the maximum possible efficiency of the strengthening technique used.

$$
P_{f}=2 V_{f}=2 E_{f} \times \varepsilon_{f, e f f} \times A_{f, e f f}
$$

where $A_{f, e f f}=A_{f},\left(d_{s} / s_{f}\right)=n \times b_{f} \times t_{f} \times\left(d_{s} / s_{f}\right)$

in which $V_{f}$ is the contribution of the bonded CFRP strips to the shear strength, $d_{s}$ is the effective depth of the beam, $s_{f}$ is the spacing between bonded strips, $A_{f, e f f}, n, E_{f}$ and $t_{f}$ are the effective cross-section area, number of layers, modulus of elasticity and the effective thickness of the CFRP strip, respectively.

The real contribution of the bonded CFRP strips $P_{f}$ to the total load calculated according to the Eq.(1) were 45, 71, 39 and $70 \mathrm{kN}$ for strengthened beams CS.1, CS.2, DS.1 and DS.2 respectively. However, the corresponding results obtained experimentally were $39,57,39$ and $63 \mathrm{kN}$ respectively. What was mentioned confirms that Eq. (1) generally overestimates the contribution of the bonded CFRP strips to the shear strength of RC strengthened beams. This is due to the fact that, the concrete reaches its full contribution before the bonded CFRP sheets maintains their effective contribution. As a result, when CFRP sheets reached their effective contribution, the concrete lost a part of its contribution (lost a part of aggregate interlock). And this interprets the local concrete crushing along the path of the main shear cracks: the concrete reached its ultimate strain before the failure occurred. As a result, a local crushing in concrete along the path of main shear crack was observed in case of strengthened beams provided with U-jacket sheets. Consequently, the different codes take that into considerations. Whereas, ACI code [2] limits the effective strain of the CFRP sheets $\left(\varepsilon_{f, e f f}\right)$ with the value $0.004\left(\varepsilon_{f, e f f} \leq 0.004\right)$ in order to control shear crack width and loss of aggregate interlock.

\section{Structural Ductility}

Ductility of R.C. beams strengthened externally by means of bonded reinforcement could be measured based on structural characteristics [19] such as: mid-span deflection, curvature, or energy absorption capacity as represented by the area under the load-deflection curve. The different codes don't mention any ductility requirements for beams failed mainly due to shear. Although the control beams failed mainly due to shear (traditional shear) don't provide any ductile behaviour, the beams strengthened with U-jacket CFRP sheets showed an acceptable ductile behaviour, especially for beams provided with internal stirrups. 
Based on the service load, the ductility index $\mu_{D}$ could be measured as the mid-span deflection at peak load $\Delta_{l}$ over that corresponding to the service load $\Delta_{2}$. Table 2 shows the ductility index $\mu_{D}$ for the different tested beams based on the service load. From Table 2, it is concluded that the strengthened beams provided with U-jacket CFRP sheets showed a reasonable improvement in the measured ductility in comparison with the corresponding control beam, particularly in case of beam provided with internal stirrups.

\section{Calculated Effective CFRP Strain}

The shear capacity of the strengthened beam may be calculated in a similar way as the control beam (without strengthening). As it is known that, according to ACI code $[1,2]$, the shear capacity of the control beam is estimated based on truss analogy. As a consequence, the nominal shear strength of a RC beam strengthened in shear by means of externally bonded CFRP side strips, $v_{n}$, can be predicted as a sum of the shear resisting contributions of the concrete $\left(v_{c}\right)$, the steel stirrups $\left(v_{s}\right)$ and the bonded fiber $\left(v_{f}\right)$ according to Eq. (2):

$v_{n}=v_{c}+v_{s}+v_{f}$

where: $v_{c}=0.1578 \sqrt{f_{c}^{\prime}}+\frac{17.24 \rho_{s} F_{u} d_{s}}{M_{u}}$

$v_{s}=\frac{A_{s t} f_{y, s t}}{s_{s} b_{w}}\left(\cot \theta+\cot \alpha_{s}\right) \sin \alpha_{s}$

$v_{f}=\frac{A_{w f} E_{f} \varepsilon_{f, e f f}}{s_{f} b_{w}}\left(\cot \theta+\cot \alpha_{s}\right) \sin \alpha_{f} \times \frac{d_{f}}{d_{s}}$

in which $A_{s t}$ and $A_{w f}$ are the cross-sectional area of the internal and external web reinforcement respectively, $f_{y . s t}$ is the yield strength of internal web reinforcement, $f_{c}^{\prime}$ is the concrete compressive strength for cylinder, $M_{u} / F_{u}$ represents the shear span $(a)$, $d_{s} \& b_{w}$ are the effective depth and web width of the beam respectively, $s_{s} \& s_{f}$ are the spacing between internal and external web reinforcement respectively, $E_{f} \& \varepsilon_{f, e f f}$ are the modulus of elasticity and effective strain of the bonded fibre strips, $\square \square \square \square \alpha_{s} \& \alpha_{f}$ are inclination of major diagonal shear crack, steel stirrups and bonded fibers strips respectively, $d_{f}$ is the depth of the FRP sheet [= the effective depth $d_{\mathrm{s}}$ incase of rectangular section and $=\left(d_{\mathrm{s}}-t_{s}\right)$ in case of T-section] and $t_{s}$ is the thickness of the slab.

As it is mentioned before, the shear strength contribution of the externally bonded web FRP reinforcement $\left(v_{f}\right)$ depends mainly on its effective strain $\varepsilon_{f, e f f}$, see Eq. (5). As a matter of fact, there are several factors affect the induced effective strain of the bonded web FRP reinforcement, such as: the configuration of the formed main shear crack along its length, the bond strength between the FRP strips and the concrete surface, and the anchorage length. The last two parameters, i.e. the bond strength and the anchorage length, represent the anchoring force of the bonded web FRP reinforcement. Also, the local debonding of the bonded FRP web reinforcement at both sides of the main shear crack plays a significant role on the induced effective strain 
$\varepsilon_{f, e f f}$. Bonded U-wraps or bonded face plies - FRP systems that don't enclose the entire section (two- and three- sided wraps) have been observed to delaminate from the concrete before the loss of aggregate interlock of the section. For this reason, bond stresses should be analyzed to determine the usefulness of theses systems and the effective strain level that can be achieved [20]. An upper limit of the effective strain $\varepsilon_{f, e f f}$ is recommended $\left(\varepsilon_{f, e f f}=0.004\right)$ in order to control shear crack width and loss of aggregate interlock [22]. Based on the extensive and specific research data by Triantafillou [20] and Khalifa [21], ACI code [2] proposed a more deterministic approach to predict the effective strain $\varepsilon_{f, e f f}$ as a function of the bond-reduction coefficient $k_{v}$ and the ultimate strain of the bonded fibre strips $\varepsilon_{f, u}$, see Eq. (6). As a consequence, the effective strain of the bonded fibre strips is calculated using a bondreduction coefficient $k_{v}$ applicable to shear as follows:-

$\varepsilon_{f, e f f}=k_{v} \times \varepsilon_{f, u} \leq 0.004$

in which $\varepsilon_{f, u}$ is the ultimate strain of the bonded fibre strips.

The bond-reduction coefficient $k_{v}$ is a function of the concrete strength, the type of wrapping scheme used, and the stiffness of the bonded fibre sheet. The bond-reduction coefficient $k_{v}$ can be computed from Eqs.(7) through (10) [21]. The active bond length $L_{e}$ obtained according to Eq.(8) is defined as the length over which the majority of the bond stresses is maintained. The bond-reduction coefficient $k_{v}$ also depends on two modification factors, $k_{l}$ and $k_{2}$, that account for the concrete strength and the type of wrapping scheme used, respectively, see Eqs. (9) and (10). The obtained expressions were derived based on the fact that the contributions of the bonded web FRP reinforcement equal to the difference between the maximum load of the strengthened beam and that of the control beam, and assuming diagonal shear crack with $\theta=45^{\circ}$.

$$
\begin{aligned}
& k_{v}=\frac{k_{1} k_{2} L_{e}}{11900 \varepsilon_{f, u}} \leq 0.75 \\
& L_{e}=\frac{23300}{\left(n t_{f} E_{f}\right)^{0.58}} \\
& k_{1}=\left(\frac{f_{c}^{\prime}}{27}\right)^{\frac{2}{3}} \\
& k_{2}=\frac{d_{f}-L_{e}}{d_{f}} \rightarrow \cdots(\text { for } U-\text { Jacket sheets }) \\
& k_{2}=\frac{d_{f}-2 L_{e}}{d_{f}} \rightarrow \quad(\text { for sheets bonded to sides only })
\end{aligned}
$$

in which $n$ is the number of layers the bonded fibre strips, $t_{f}$ is the effective thickness of the bonded fibre sheet, and $\varepsilon_{f, u}$ is ultimate strain of the bonded fibre strips.

The effective strain of the CFRP bonded sheets required to estimate the shear strength of the strengthened beams was calculated according to the proposed ACI model [2], see Eq. (6). The predicted results showed a considerable approach to the 
obtained experimental results "mean strain of CFRP sheets $\varepsilon_{f \text {,mean }}$ ", see Fig. 12. As a consequence, the predicted results approved the applicability of the proposed expressions suggested to predict the effective strain of the bonded CFRP sheets.

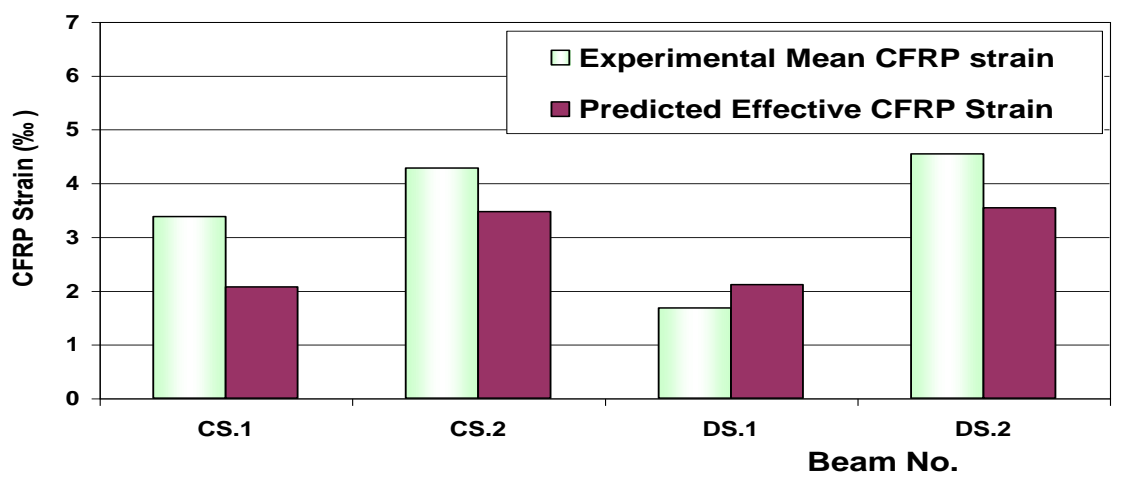

Fig. 12: Predicted effective CFRP strain and experimental mean CFRP strain

\section{CONCLUSIONS AND RECOMMENDATIONS}

From the analysis of both the experimental and the analytical results, the following conclusions and recommendations can be stated:

* The strengthening technique applied to enhance the shear strength of R.C. beams showed an acceptable efficiency, especially in case of beams strengthened by means of U-jacket CFRP sheets.

* Although the failure mode for the different beams was a brittle one, the strengthened beams provided with U-jacket CFRP sheets showed more or less a ductile behavior at a higher loading level up to a load level just before failure. As a consequence, these beams approved an acceptable enhancement in the structural ductility.

* Three mechanisms of failure were recognized for the tested beams. The first one was the traditional brittle shear and occurred in the control beams. The second mechanism was a shear one accompanied with a partial delamination of the outer CFRP sheets and occurred in case of the strengthened beams with sheets bonded to their sides only. The third mechanism was a shear one accompanied with cut off the outer CFRP sheet as well as crushing of concrete in the shear crack path's region. Such a failure mechanism was recorded in case of the U-jacketed beams.

* The suggested model by ACI code to predict the effective strain of the bonded side CFRP sheets, which is necessary to estimate the shear strength of strengthened beams, showed a considerable approach to the obtained experimental results.

\section{REFERENCES}

[1] American Concrete Institute (ACI) Committee 318 (2008); "Building Code Requirements for Structural Concrete (ACI 318-08) and Commentary", Farmington Hills, Michigan, USA.

[2] American Concrete Institute (ACI) 440.2R-08 (2008); "Guides for the Design and Construction of Externally Bonded FRP System for Strengthening Concrete 
Structures", Rep. No. 440.2R-08, Farmington Hills, Michigan, USA.

[3] Farghal, O.A. (2000); "Strengthening of R.C. Beams by means Externally Bonded CFRP Laminates - Improved Model for Plate-End Shear", Ph. D. thesis, Department of Civil Engineering, KUL, Leuven, Belgium.

[4] Norris, T. Saadatmanesh, H. and Ehsani, M. R. (1997); "Shear and Flexural Strengthening of RC Beams with Carbon Fiber Sheets," ASCE Journal of Structural Engineering, Vol. 123, Issue 7, July 1997, pp. 903-911.

[5] Amir, M. and Saadatmanesh H. (1998); "Analytical Study of RC Beams Strengthened with Web-Bonded Fiber-Reinforced Plastics Plates or Fabrics," ACI Structural Journal, Vol. 95, Issue 3, May 1998.

[6] Chaallal, O., Nollet, M. J. and Perraton, D. (1998); "Shear Strengthening of RC Beams by Externally Bonded Side CFRP Strips," Journal of Composites for Constructions ASCE, Vol. 2, No. 2, May 1998, pp. 111- 113.

[7] Chen, J. F. and Teng, J. G. (2001); "Shear Capacity of FRP-Strengthened RC Beams: FRP Debonding," Journal of Construction \& Building Materials, Vol. 2, Issue 1, February 2003, pp. 27-41.

[8] Alex, Li., Diagana, Ch. and Yves, D. (2001); "CFRP Contribution to Shear Capacity of Strengthened RC Beams," Journal of Engineering Structures, Vol. 23, Issue 10, October 2001, pp. 1212-1220.

[9] Alex, Li., Jules, A. and Yves, D. (2001); "Shear Strengthening of RC Beams with Externally Bonded CFRP Sheets," Journal of Structural Engineering, Vol. 2, No. 2, 2001, pp. 111- 117.

[10] Ahmed, O. A. F. (2004); "Shear Strengthening of R.C. Beams Using Carbon Fiber Reinforced Polymer (CFRP) Sheets," International Conference on Structural \& Geotechnical Engineering and Construction Technology,23 - 25 March 2004, Mansoura, Egypt, pp. 679-692.

[11]Islam, M. R., Mansur M. A. and Maalej M. (2005); "Shear Strengthening RC Deep Beams Using Externally Bonded FRP Systems," Journal of Cement \& Concrete Composites, Vol. 27, Issue 3, March 2005, pp. 413- 420.

[12] Adhikary, B. B. and Mutsuyoshi H. (2006); "Shear Strengthening RC Deep Beams with Web-Bonded Continuous Steel Plates," Journal of Construction \& Building Materials, Vol. 20, Issue 5, June 2006, pp. 296- 307.

[13] Pellegrino, C. and Modena C. (2006); "Fiber-Reinforced Polymer Shear Strengthening of RC Beams: Experimental Study and Analytical Modeling," ACI Structural Journal, Vol. 103, Issue 5, September 2006, pp. 720- 728.

[14] Bianco, V., Barros, J.A.O. and Monti, G. (2009); "Bond Model of NSM-FRP Strips in the Context of the Shear Strengthening of RC Beams" Journal of Structural Engineering, Vol. 135, Issue 6, May 2009, pp. 135- 147.

[15] Costa, I. G., and Barros, J.A.O. (2010); "Flexural and Shear Strengthening of RC Beams with Composites Materials - The Influence of Cutting Steel Stirrups to Install CFRP Strips," Journal of Cement \& Concrete Composites, Vol. 32, Issue 7, August 2010, pp. 544- 553.

[16] Khalfa, A. and Nani A. (2000); "Improving Shear Capacity of Existing RC TSection Beams Using CFRP Composites," Journal of Cement \& Concrete Composites, Vol. 22, Issue 3, June 2000, pp. 165- 174.

[17] Salvador, J. E. D, and Joaquim, A.O. B. (2008);“" Shear Strengthening of T Cross Section Reinforced Concrete Beams by Near-Surface Mounted Technique," 
Journal of Composites for Constructions ASCE, Vol. 12, No. 3, February 2012, pp. 162- 171.

[18] SIKA Egypt (2006); "Sika Carbodur System, P.C.26: Specification for Structural Strengthening with SIKA Carbodur system", Design Guideline, Egypt.

[19] Swamy, N., Mukhopadhyaya, P. and Lynsdale, C. (1997); "Ductility Consideration in Using GFRP Sheets to Strengthen and Upgrade Structures," $3^{\text {rd }}$ International Symposium on Non-Metallic (FRP) Reinforcement for Concrete Structure, Sapporo, Japan, (1997), Vol. 1, pp. 637- 644.

[20] Triantafillou, T. C. (1998); "Shear Strengthening of R. C. Beams Using EpoxyBonded FRP Composites," ACI Structural Journal, Vol. 95, No. 2, March- April 1998, pp. $107-115$.

[21] Khalifa, A., Tumialan, G., Nanni, A. and Belarbi, A. (1999); "Shear Strengthening of Continuous R.C. Beams Using Externally Bonded CFP Sheets" Proceeding of the $4^{\text {th }}$ International Symposium - Fiber Reinforced Polymer Reinforcement for R.C.Structures - Maryland, USA, October 1999, pp.995- 1003 [22] Modifidi, A. and Chaallal, O. (2011); "Shear Strengthening of R.C. Beams with EB FRP: Influencing Factors and Conceptual Debonding Model" Journal of Composites for Constructions ASCE, Vol. 15, No. 1, February 2011, pp. 62- 74.

\section{تقوية الكمرات الخرسانية المسلحة ذات المقطع على شكل حرف T والمقواة في القص بإستخدام شرائح ألياف الكربون البوليمرية}

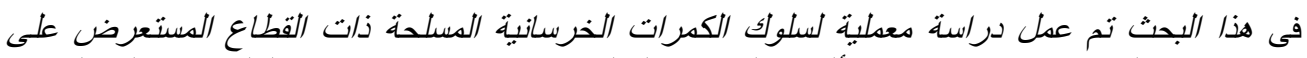

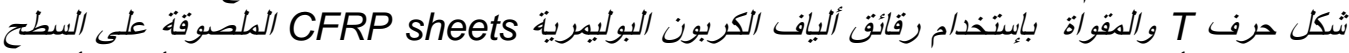

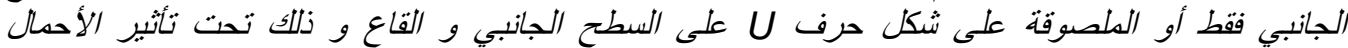

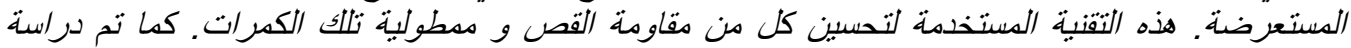

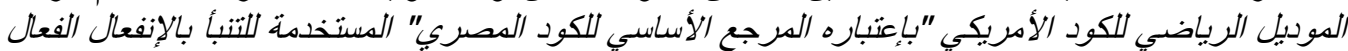

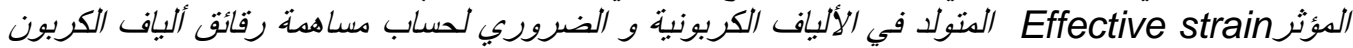

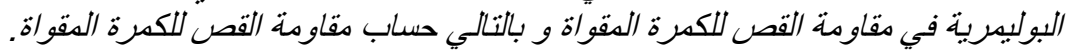

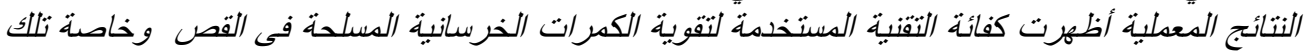

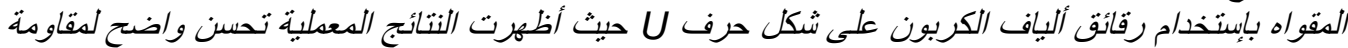

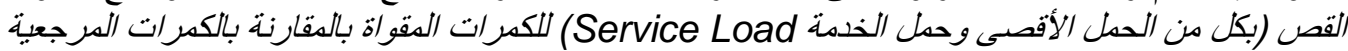

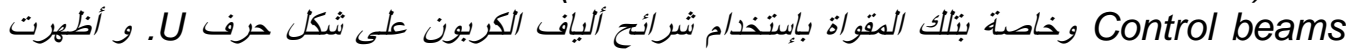

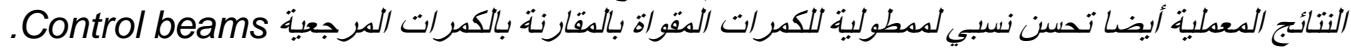

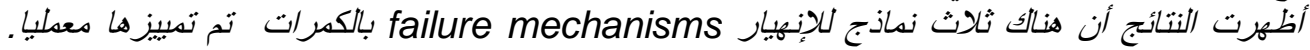

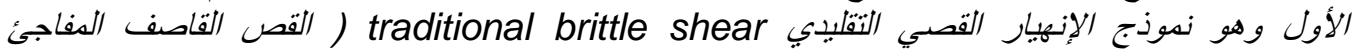
(Sudden brittle shear

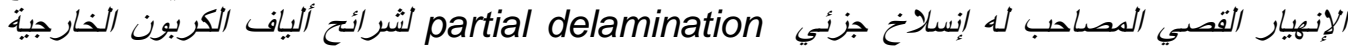

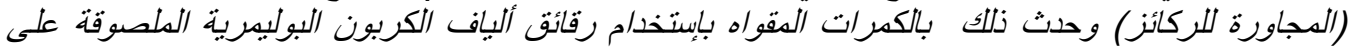

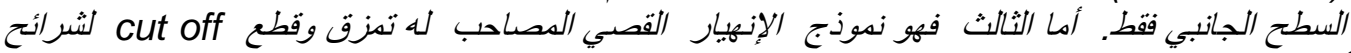

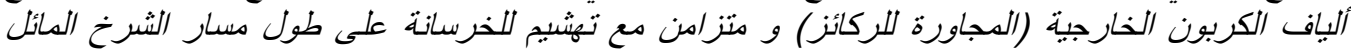

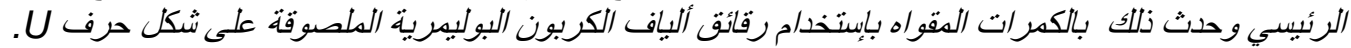

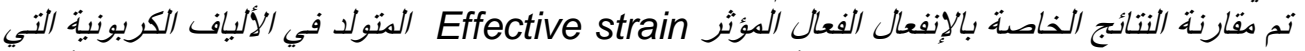

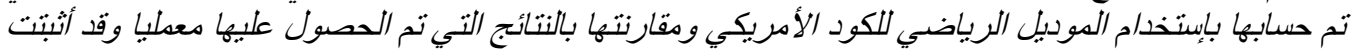

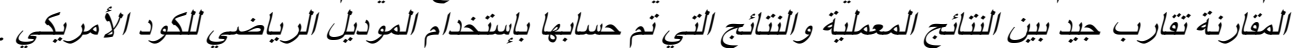

